\title{
Effect of Aluminum upon Phase Changes and Age-Hardening Behaviors in 17-7 PH Stainless Steel
}

\author{
By Natsuo YUKAWA, ${ }^{* *}$ Masayoshi MIZUTANI, ${ }^{* * *}$ and Hiroyasu SAKA**
}

\begin{abstract}
Synopsis
In order to clarify the nature of age-hardening in 17-7 PH stainless steel, the constitution and the age-hardening characteristics of alloys containing 16 to $19 \% \mathrm{Cr}, 7 \% \mathrm{Ni}, 0$ to $10 \% \mathrm{Al}$ and the remainder iron were investigated physico-metallurgically. Phases and phase transformations occurring in the $(17 \mathrm{Cr}-7 \mathrm{Ni}-<0.01 \mathrm{C}-\mathrm{Fe})-\mathrm{Al}$ system and in a commercial $17-7 \mathrm{PH}$ steel were determined, and also the effect of aluminum upon the the agehardening of this steel system was described. It was shown that the maximum hardening is obtained in alloys which consist of martensite and a small amount of $\delta$-ferrite with about $1.5 \% \mathrm{Al}$ which corresponds to the aluminum content of the standard 17-7 PH steel, and that the remarkable age-hardenability of the steel is attributed to the precipitation of $\alpha^{\prime}$ (ordered boc of $\mathrm{CsCl}$ type based on $\mathrm{NiAl}$ ) from martensite matrix.
\end{abstract}

\section{Introduction}

Precipitation hardening stainless steels have been developed to meet the material demands associated with the design and construction of aircraft for high speed flight. Among these steels 17-7 PH stainless steel is a typical semi-austenitic precipitation hardenable stainless steel. It essentially consists of austenite in the solution annealed condition (condition $A$ ), under which it can undergo relatively severe cold-working. In order to produce martensite, the material is then customarily annealed for $1.5 \mathrm{hr}$ at $760^{\circ} \mathrm{C}$ and air cooled (condition $T$ ). Finally, the martensite is precipitation-hardened, e.g., for $0.5 \mathrm{hr}$ at $565^{\circ} \mathrm{C}$ (condition TH 1050 ).

High-strength mechanical properties and good corrosion resistance as well as superior weldability of this material have spurred a lot of investigators onto the studies of this material. These studies ${ }^{3)-10)}$ were mainly concentrated on the precipitation-hardening mechanism of this steel, and at present it is well established that the major precipitate in the martensite matrix has the structure of CsCl type, that is, ordered ferrite which has been nominally referred to as $\mathrm{NiAl}^{\dagger}$. On the other hand, in spite of its engineering importance, the effect of aluminum on the hardening characteristics and the constitution of this steel was relatively unknown.

Recently Furukawa ${ }^{8), 9)}$ investigated the effect of aluminum on the age-hardening of this steel in the relatively limited range of aluminum : 0.75 to $1.5 \%$ $\mathrm{Al}$, but no systematic study based on the phase equilibrium has yet been carried out.

Accordingly, in order to clarify the nature of agehardening in 17-7 $\mathrm{PH}$ steel, the constitution of alloys containing 16 to $19 \% \mathrm{Cr}, 7 \% \mathrm{Ni}, 0$ to $10 \% \mathrm{Al}$, and re- mainder iron was studied physico-metallurgically, and also the effect of aluminum upon their age-hardening characteristics was investigated.

\section{Specimens and Experimental Methods}

Marterials used for this study are shown in Table 1. In order to investigate the effect of aluminum as well as chromium on the constitution and the age-hardenability, two series of alloys, each containing various amounts of aluminum with slightly different chromium contents, were prepared.

The one is designated as $A$ series which contains about $16 \% \mathrm{Cr}, 7 \% \mathrm{Ni}$, and aluminum varying from $0 \%$ to $10 \%$, the other is designated as $B$ series containing about $19 \% \mathrm{Cr}, 7 \% \mathrm{Ni}$, and aluminum varying from $0 \%$ to $3 \%$. In addition to these alloys, a commercial heat of 17-7 PH bar which was supplied by Nippon Yakin Kogyo Co., Ltd. was used. Here it should be noted that the carbon content of both $A$ and $B$ series is decreased to approximately one-tenth of that of commercial $17-7 \mathrm{PH}(0.07 \% \mathrm{G})$, in order to reduce the effect of carbide precipitation.

Both series of alloys were prepared by vacuum melting and vacuum casting, yielding ingots of about $600 \mathrm{~g}$ each, and hot-swaged to bars $12 \mathrm{~mm}$ in diameter. To provide thin foils for electron microscopy the bar was cold-rolled, with several intermediate annealings, to the thickness of about $0.3 \mathrm{~mm}$.

The heat treatments employed were as follows :

(1) A treatment : $1050^{\circ} \mathrm{C} \times 1 \mathrm{hr} \mathrm{W} . \mathrm{Q}$.

(2) $T$ treatment: $760^{\circ} \mathrm{C} \times 1.5 \mathrm{hr}$ W. Q. plus $0^{\circ} \mathrm{C} \times 0.5 \mathrm{hr}$

(3) $\mathrm{AH}$ treatment ( $\mathrm{TH}$ treatment for commercial $17-7 \mathrm{PH}): \quad 500^{\circ} \mathrm{C}, 550{ }^{\circ} \mathrm{C}$, and $600^{\circ} \mathrm{C} \times 10 \mathrm{~min}$ to $500 \mathrm{hr}, \mathrm{W} . \mathrm{Q}$.

After the heat treatments mentioned above, dilatometric, thermomagnetic, electrical resistivity, and hardness measurements as well as microscopical examinations (both optical and electron microscopy) were carried out. In addition, in order to obtain the sectional diagrams, detailed microscopical examinations were carried out on the specimens quenched into water from various temperatures.

To reveal microstructures, electrolytic etching in aqueous solutions of $10 \%$ oxalic acid or sulfuric acid, or chemical etching in a solution consisting of hydrochloric acid and $\mathrm{FeCl}_{3}$ were selectively used depending on the condition of structures. Extraction replicas

* Originally published in J. Japan Inst. Metals (References 1), 2)) in Japanese. English version received October $26,1968$.

** Department of Metallurgy, Faculty of Engineering, Nagoya University, Chikusa-ku, Nagoya 464.

*** Now at: Toyota Central Research and Development Laboratories Inc., Hisakata, Showa-ku, Nagoya 466.

$\dagger \quad$ Recently Marcus et. al. $\left.{ }^{6}, 7\right)$ have proposed that the composition of this precipitate is $(\mathrm{Ni}, \mathrm{Cr}, \mathrm{Fe})_{1-y} \mathrm{Al}$, where $y$ may be + or - . 
Table 1. Chemical composition of specimens

\begin{tabular}{|c|c|c|c|c|c|c|c|}
\hline & C & $\mathrm{Si}$ & $\mathrm{Mn}$ & $\mathrm{Cr}$ & $\mathrm{Ni}$ & $\mathrm{Al}$ & $\mathrm{Fe}$ \\
\hline 17-7 $\mathrm{PH}^{*}$ & 0.072 & 0.44 & 0.84 & 16.53 & 7.22 & 1.25 & bal. \\
\hline$A-1$ & 0.0038 & 0.06 & 0.01 & 15.80 & 7.09 & 0.002 & $"$ \\
\hline$A-2$ & 0.0071 & 0.12 & $"$ & 15.31 & 7.27 & 0.47 & " \\
\hline$A-3$ & 0.0063 & 0.06 & ", & 14.95 & 7.42 & 1.20 & $"$ \\
\hline$A-4$ & 0.0035 & 0.07 & ", & 16.16 & 7.45 & 1.48 & $"$ \\
\hline$A-5$ & 0.0060 & ", & , & 15.37 & 7.72 & 1.88 & " \\
\hline$A-6$ & 0.0042 & 0.06 & " & 16.37 & 7.19 & 2.69 & " \\
\hline$A-7$ & 0.0073 & 0.04 & , & 16.10 & 7.14 & 3.94 & " \\
\hline$A-8$ & 0.0160 & 0.06 & ", & 16.36 & 7.23 & 5.40 & $"$ \\
\hline$A-9$ & 0.04 & $"$ & $"$ & 16.46 & 7.34 & 10.09 & " \\
\hline$B-1$ & 0.006 & 0.07 & n.d.** & 19.01 & 7.08 & $\operatorname{tr}$ & $"$ \\
\hline$B-2$ & 0.007 & 0.13 &, & 19.66 & 6.93 & 0.42 & " \\
\hline$B-3$ & 0.010 & 0.07 & ", & 18.49 & 6.97 & 1.24 & ", \\
\hline$B-4$ & 0.014 & 0.21 & ", & 18.54 & 7.18 & 1.93 & $"$ \\
\hline$B-5$ & 0.013 & 0.13 & , & 19.36 & 6.38 & 2.95 & " \\
\hline
\end{tabular}

* P: $0.016, \quad \mathrm{~S}: 0.009, \mathrm{Cu}: 0.14, \mathrm{Mo}: 0.13$.

** n.d. : not determined.

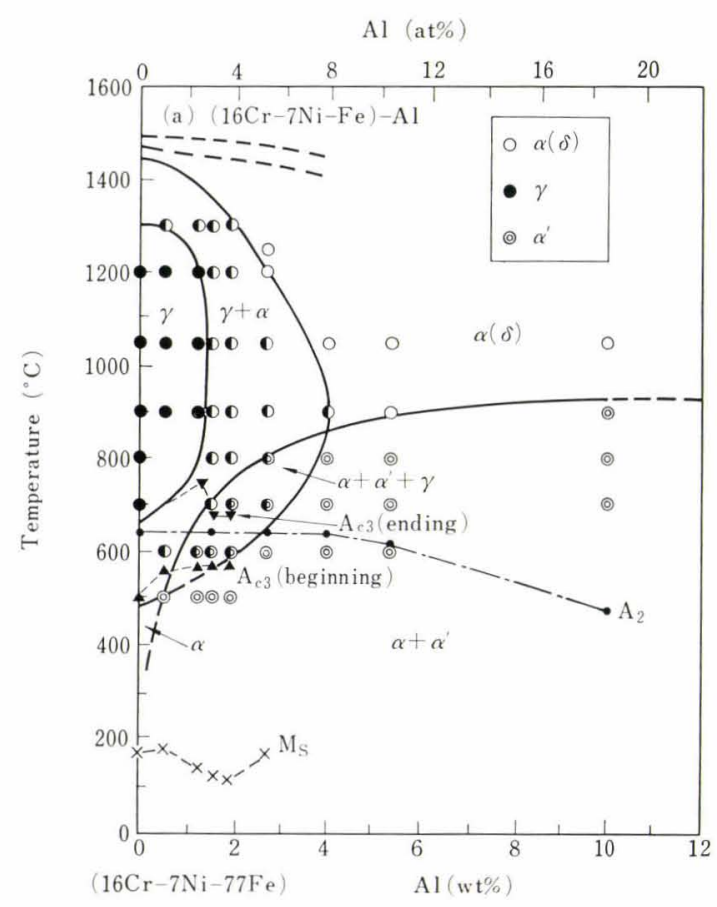

(a)

were prepared by electrolytic etching in an aqueous solution of $10 \%$ sulfuric acid for stripping the deposited carbon film. Thin foils were prepared by electropolishing in a solution containing 4 vol. of sulfuric acid and 6 vol. of phosphoric acid using Bollmann method.

\section{Experimental Results and Discussion}

\section{1. (17Cr-7Ni-<0.01C-Fe)-Al Sectional Diagram}

The effect of aluminum on the phase transformations in both $A$ and $B$ series of alloys was studied physicometallurgically, and through the study the $(16 \mathrm{Cr}-$ $7 \mathrm{Ni}-\mathrm{Fe})-\mathrm{Al}$ and $(19 \mathrm{Cr}-7 \mathrm{Ni}-\mathrm{Fe})-\mathrm{Al}$ sectional diagrams

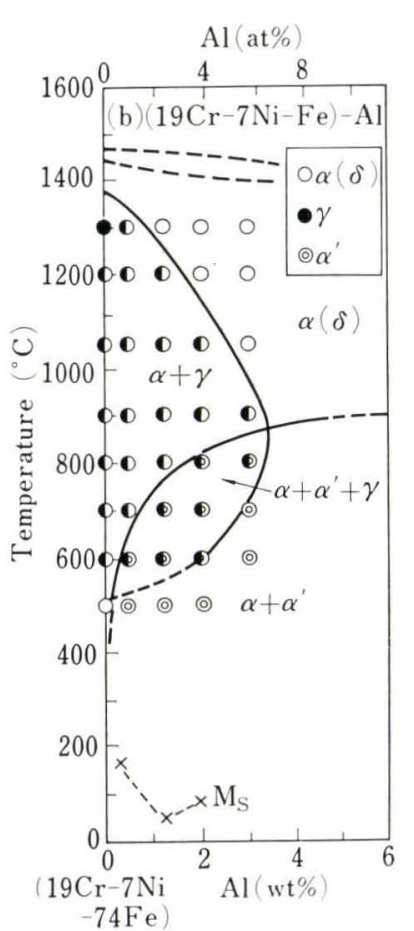

Fig. 1.
(a) $\quad(16 \mathrm{Cr}-7 \mathrm{Ni}-<0.01 \mathrm{C}-\mathrm{Fe})-$ Al sectional diagram
(b) $(19 \mathrm{Cr}-7 \mathrm{Ni}-<0.01 \mathrm{C}-\mathrm{Fe})-$ Al sectional diagram

(b)

as shown in Fig. $\mathrm{l}$ (a) and (b) were determined. In these diagrams the points of $\mathrm{A}_{\mathrm{c}_{3}}, \mathrm{M}_{\mathrm{s}}$, and $\mathrm{A}_{2}$ obtained by thermodilatometric and/or thermo-magnetic analyses, of which detailed experimental data will be shown in a later section, are plotted. The microstructures above $1050^{\circ} \mathrm{C}$ were determined on the specimens quenched from the temperatures indicated and those between $900^{\circ}$ and $500^{\circ} \mathrm{C}$ were on the specimens aged for a long time at each temperature after $A$ treatment (1 $050^{\circ} \mathrm{C} \times 1 \mathrm{hr}$ W. Q.).

Figure 2 shows the $(17 \mathrm{Cr}-7 \mathrm{Ni}-\mathrm{Fe})-\mathrm{Al}$ sectional diagram deduced by interpolation of Fig. 1 (a) and (b). It is shown that in this system there exist $\gamma(f c c), \alpha$ 


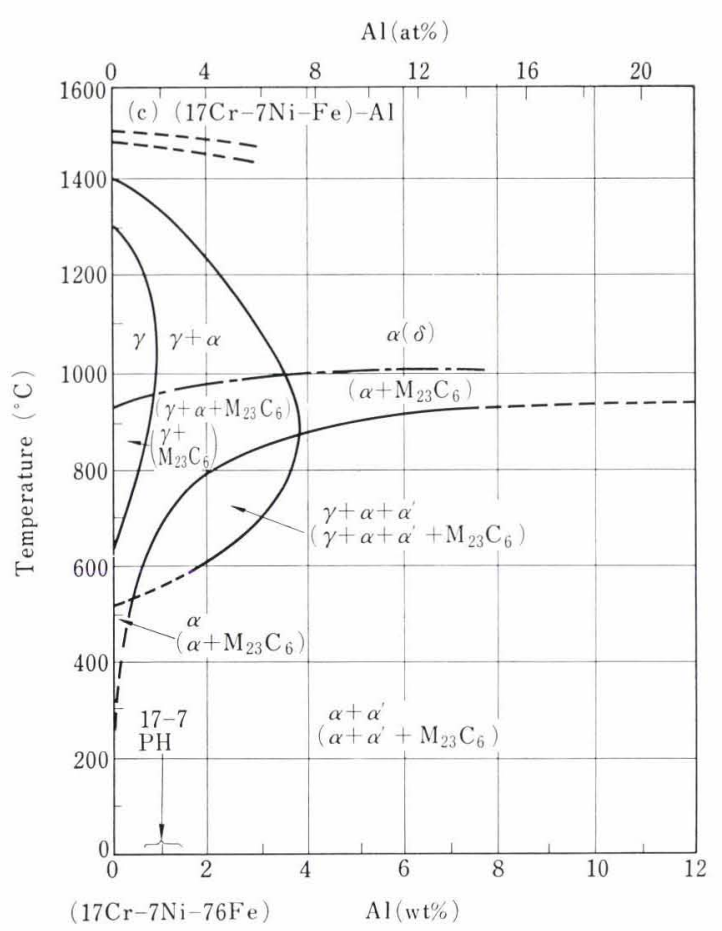

Fig. 2. (17 $\mathrm{Cr}-7 \mathrm{Ni}-<0.01 \mathrm{C}-\mathrm{Fe})-\mathrm{Al}$ sectional diagram, where fields put in brackets are applied to alloys with $0.07 \% \mathrm{C}$

(bcc: isomorphous with $\delta$-phase), and $\alpha^{\prime}$ (ordered bcc, intermetallic compound consisting mainly of $\mathrm{NiAl}$ ) phases. Among these phases, $\gamma$ forms a single phase region for the alloys containing aluminum up to $1 \%$ and at temperatures above about $700^{\circ} \mathrm{C}$, which is surrounded with the so-called $\alpha+\gamma$-loop extending up to $4 \% \mathrm{Al}$ and at temperatures above about $530^{\circ} \mathrm{C}$. On the other hand, regions of $\alpha+\alpha^{\prime}$ and $\alpha+\alpha^{\prime}+\gamma$ occur at lower temperatures. In this case, $\alpha \rightleftarrows \alpha^{\prime}$ transformation points increase precipitously with aluminum addition up to 2 to $4 \%$ but gradually with further aluminum addition, to reach about $900^{\circ} \mathrm{C}$ for a $10 \% \mathrm{Al}$ alloy.

In comparison with Fig. 1 (a) and Fig. 1 (b) it follows that the effect of chromium addition on these phase transformations is only to shift the $\gamma / \gamma+\alpha$ phase boundary to the lower aluminum side, and that in practice chromium has little effect on $\alpha \rightleftarrows \alpha^{\prime}$ reaction in these systems.

In those alloys which were practically free from carbon, both $A$ and $B$ series, $\mathrm{M}_{\mathrm{s}}$ points of $\gamma$-phase were so high that martensite transformation occurred during cooling in $A$ treatment. Thus no austenitic-conditioning treatment ( $T$ treatment) was required to obtain martensite matrix, $\alpha_{\mathrm{M}}$. Subsequent aging between $400^{\circ}$ and $600^{\circ} \mathrm{C}$ resulted in the precipitation of $\alpha^{\prime}$ from $\alpha_{\mathrm{M}}$ as well as from $\delta$-phase. In the alloys of higher aluminum content which consisted mainly of $\delta$-phase, however, $\alpha^{\prime}$ precipitated submicroscopically from $\delta$-phase during cooling in $A$ treatment. Abovementioned precipitation morphologies of $\alpha^{\prime}$ will be discussed later more in detail.

On the other hand, in the commercial 17-7 PH, of which carbon content is about $0.07 \%, \mathrm{M}_{23} \mathrm{C}_{6}$ carbide precipitation occurred, thus we must take into account the following additional transformations: $\gamma \rightleftarrows$ $\mathrm{M}_{23} \mathrm{C}_{6}, \alpha \rightleftarrows \mathrm{M}_{23} \mathrm{C}_{6}$, and $\gamma \rightleftarrows \alpha+\mathrm{M}_{23} \mathrm{C}_{6}$. Consequently, in this case the sectional diagram will be modified qualitatively by adding parenthesized $\mathrm{M}_{23} \mathrm{C}_{6}$ as shown in Fig. 2.

Furthermore, because of its high carbon content, $\gamma$-phase in this alloy is stable enough to retain at the room temperature after $A$ treatment. By annealing this metastable $\gamma$-phase at about $800^{\circ} \mathrm{C}$, it becomes unstable through the precipitation of $\mathrm{M}_{23} \mathrm{C}_{6}$ carbide ${ }^{11), 12)}$ (the dot-dash-line in Fig. 2 shows the estimated solubility curve ${ }^{13)}$ of $\mathrm{M}_{23} \mathrm{C}_{6}$ in matrix), and is transformed into martensite $\left(\alpha_{\mathrm{N}}\right)$ during subsequent cooling. On aging between $400^{\circ}$ and $600^{\circ} \mathrm{C}$, $\alpha^{\prime}$ as well as $\mathrm{M}_{23} \mathrm{C}_{6}$ dispersedly precipitates from $\alpha_{\mathrm{M}}$ and $\delta$, but the amount of $\mathrm{M}_{23} \mathrm{C}_{6}$ is very small and it can be considered that the major precipitation reaction in this case is $\alpha$ ( $\delta$ or $\alpha_{\mathrm{M}}$ ) $\rightarrow \alpha^{\prime}$.

As mentioned previously, the effect of chromium content which varies in the specified range of composition of the commercial 17-7 PH steel, i.e. 17 to $19 \%$, on the phase transformations in this system is found to be insignificant. Accordingly, hereafter the major part of discussion will be made on the experimental results obtained from the commercial 17-7 PH and $A$ series alloys.

\section{Thermo-dilatometric and Magnetic Analyses, and Elec- trical Resistivity Measurement}

In order to reveal the transformation behavior of these materials, the thermo-dilatometric and -magnetic analyses as well as electrical resistivity measurement were carried out.

Specimens used were $5 \mathrm{~mm}$ in diameter and $80 \mathrm{~mm}$ in length and had been previously subjected to either $A$ or $A H$ treatment for both $A$ and $B$ series, or $T$ or TH treatment for the commercial 17-7 PH steel.

Figures 3 and 4 show some typical examples of these results. In Fig. 3 (b), the curve ' $\mathrm{C}$ ' which was taken on $1.5 \% \mathrm{Al}$ alloy quenched from $1050^{\circ} \mathrm{C}$ showed two contractions near $350^{\circ}$ and $600^{\circ} \mathrm{C}$ on heating, respectively, while the curve ' $\mathrm{B}$ ' which was taken on the same specimen but fully aged at $500^{\circ} \mathrm{C}$ showed only one contraction near $600^{\circ} \mathrm{C}$. By comparing these results it may be inferred that the contraction at lower temperature is attributed to the precipitation of $\alpha^{\prime}$ from $\alpha_{\mathrm{M}}$ matrix, and that the other at higher temperature corresponds to $\mathrm{A}_{\mathrm{c} 3}$, that is $\alpha \rightarrow \gamma$ reaction. On cooling, $\gamma$ was supercooled until it was transformed into martensite at $\mathrm{M}_{\mathrm{s}}$ point. The thermo-magnetic curve taken on the same specimen quenched from $1050^{\circ} \mathrm{C}$ showed no anomaly due to the precipitation of $\alpha^{\prime}$ from $\alpha_{\mathrm{M}}$, but only $\mathrm{A}_{2}$ and $\mathrm{M}_{\mathrm{s}}$ points were observed.

As the aluminum content of materials was decreased, the contraction at lower temperature on the dilatometric curves became smaller, and no contraction due to the precipitation of $\alpha^{\prime}$ was observed on the curve taken on the $0 \% \mathrm{Al}$ alloy, as was expected (see curve ' A' in Fig. 3 (a)).

On the other hand, the amount of $\delta$-phase in the solution treated condition increased with aluminum content, and the dilatometric curves obtained on 

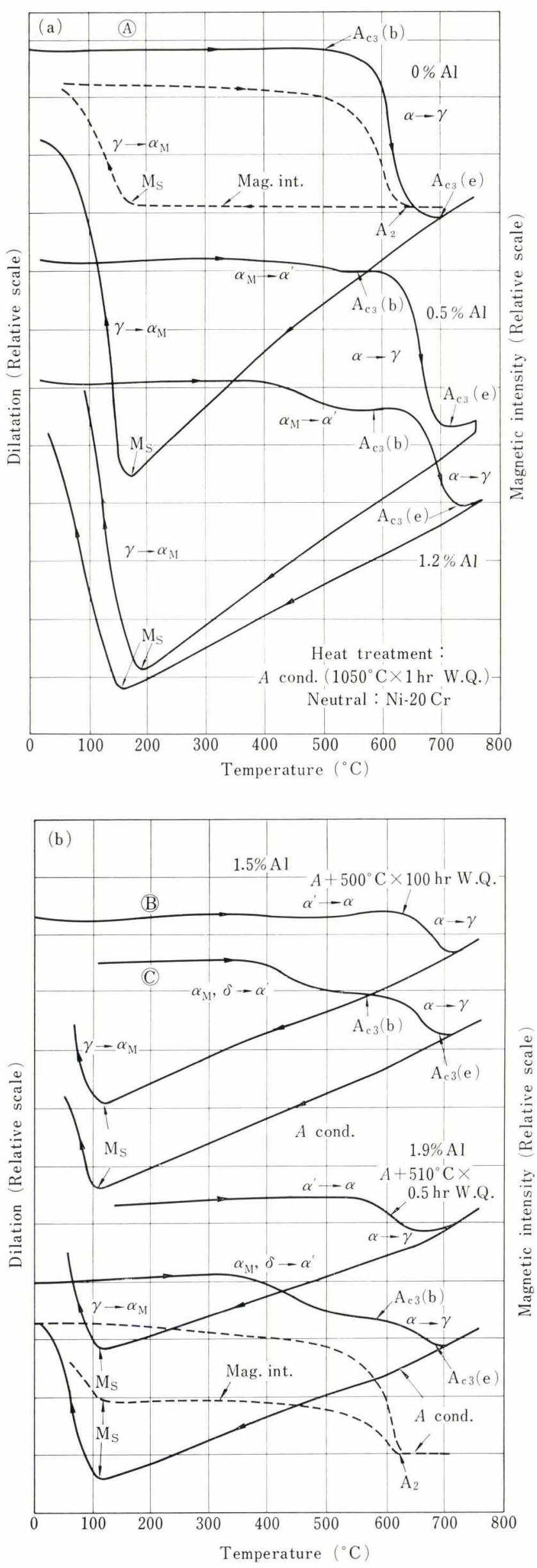

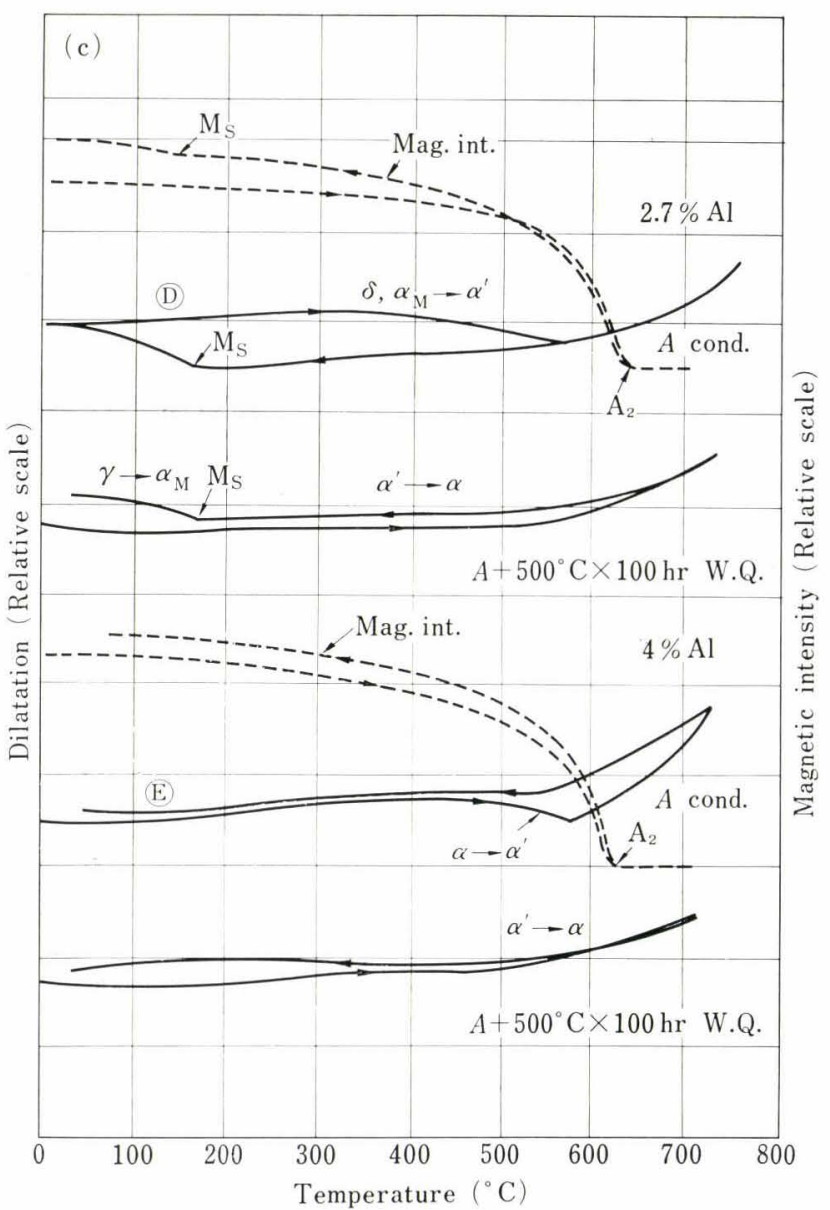

Fig. 3. (a) to (c) Thermal dilatometric and magnetic curves of $17 \mathrm{Cr}-7 \mathrm{Ni}-\mathrm{Fe}$ base alloys with various $\mathrm{Al}$ contents

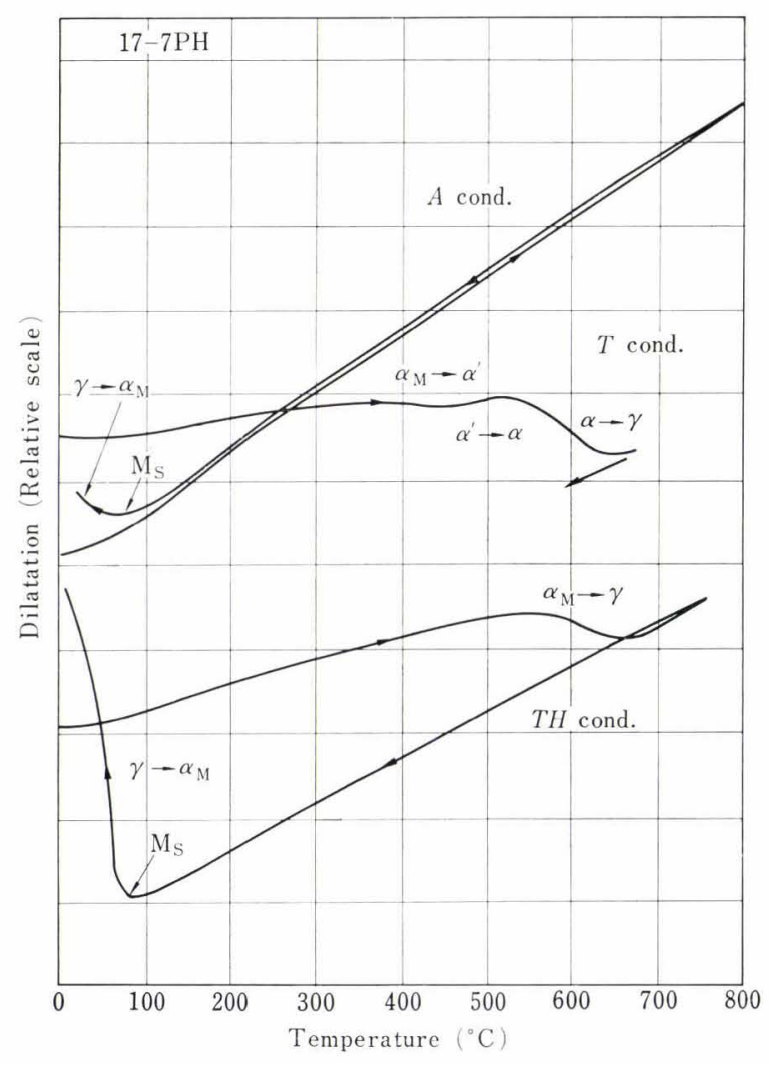

Fig. 4. Thermal dilatometric curves of 17-7 PH steel 
such alloys differed remarkably from those of the alloys with lower aluminum content (see curves ' $\mathrm{D}$ ' and ' $\mathrm{E}$ ' in Fig. 3 (c)).

In a similar manner the dilatometric curves were obtained on the commercial alloy (Fig. 4). The curve taken on the specimen as quenched from $1050^{\circ} \mathrm{C}$ ( $A$ condition) showed a very large expansion, and the anomaly was observed neither on heating nor on cooling with the exception of a slight expansion below $100^{\circ} \mathrm{C}$ on cooling owing to the martensitic transformation. As mentioned previously, the commercial alloy containing about $0.07 \% \mathrm{C}$ consists of $\gamma$ and a small amount of $\delta$ in the condition $A$. It is naturally prospected, therefore, that on heating the dilatation curve on such an alloy shows no anomaly. On heating up to $800^{\circ} \mathrm{C}$, however, $\mathrm{M}_{23} \mathrm{C}_{6}$ precipitated from $\gamma$-phase and raised its $\mathrm{M}_{\mathrm{s}}$ point, so that martensite transformation occurred on cooling. This is the reason why $T$ treatment is necessary for the commercial $17-7 \mathrm{PH}$ steel. In contrast, the other curves taken on the specimens of $T$ or $T H$ conditions (Fig. 4) were similar to that of $A$ or $A H$ conditions of $1.5 \% \mathrm{Al}$ alloy (Fig. 3 (b)), respectively. It may be considered, therefore, that the phase transformations in the commercial alloy in $T$ and $T H$ conditions are essentially equivalent to those in $A$ and $A H$ conditions of lower carbon alloys with similar aluminum contents, respectively.

Figure 5 shows the change in resistivity of 17-7 PH steel by continuous heating after $T$ and $T H$ treatments, respectively. It is noted that the feature of the curves was essentially in good agreement with those of thermal-dilatation curves as described above.

\section{Measurement of Hardness and Effect of Aluminum on the} Age-Hardening in 17-7 PH Steel

Figure 6 shows the effect of aluminum on the hardness* and the magnetic intensity of the alloys in $A$ condition. Corresponding microstructures of these alloys and that of commercial alloy in $T$ condition are shown in Photo. 1.

It is shown from these structures that the amount of $\delta$ in $A$ condition increases with aluminum content and that the alloys with aluminum content more than $4 \%$ consist of $\delta$ alone, except submicroscopical $\alpha^{\prime}$ precipitates as mentioned below. On the other hand, no appreciable change in magnetic intensity was observed with aluminum content at least up to $5.4 \% \mathrm{Al}$, as shown in Fig. 6. These results imply that $\gamma$-phase at high temperatures was transformed into martensite during $A$ treatment instead of retaining at room temperature, which is consistent with the discussion in the preceding section.

In Fig. 6, gradual increase in hardness was observed up to $2 \% \mathrm{Al}$ addition, but further addition resulted in remarkable hardening of the alloys, e.g., the hardness of the alloy containing $10 \% \mathrm{Al}$ was about $H_{V} 500$. On the other hand, the hardness of the commercial alloy in $A$ condition was very low in comparison with that of low carbon alloys because of the retained $\gamma$, but in $T$ condition it was harder than low carbon alloys

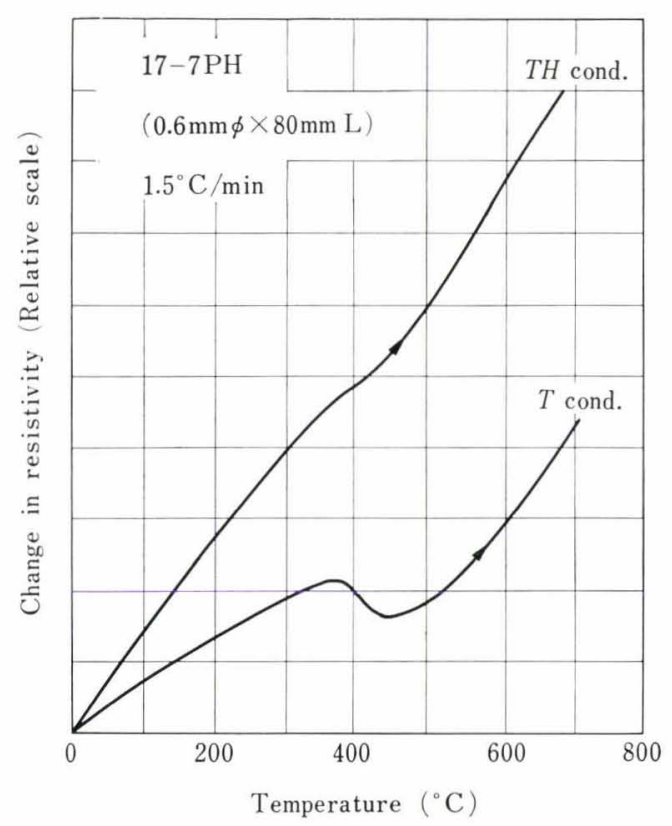

Fig. 5. Variation of resistivity of 17-7 PH steel by continuous heating after $T$ and $T H$ treatments, respectively

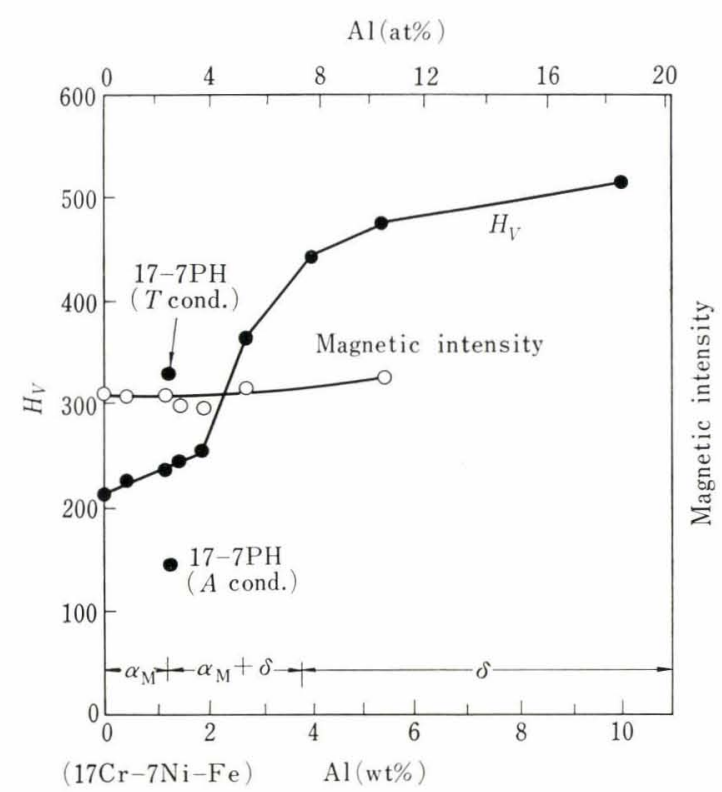

Fig. 6. Effect of $\mathrm{Al}$ on hardness and magnetic intensity of alloys after $A$ treatment

in $A$ condition by as much as $H_{V} 100$, which may be ascribed to solid solution strengthening of martensite matrix by carbon.

Figure 7 shows the change in hardness of $A$ series alloys during aging at $600^{\circ} \mathrm{C}$ after $A$ treatment, together with the results of commercial alloy after $T$ treatment. The curves for $0 \% \mathrm{Al}$ and $0.5 \% \mathrm{Al}$ alloys showed only negligibly small hardening, while the alloys containing 1 to $3 \% \mathrm{Al}$ showed striking hardening, and the maximum hardness was obtained within $1 \mathrm{hr}$. As the amount of aluminum increased the maximum hardness increased and the durations to reach peak hardness values became longer. The hardening of the commercial alloy was essentially similar to those of low carbon

* Vickers hardness was measured, which is abbreviated as $H_{V}$ in this paper. 

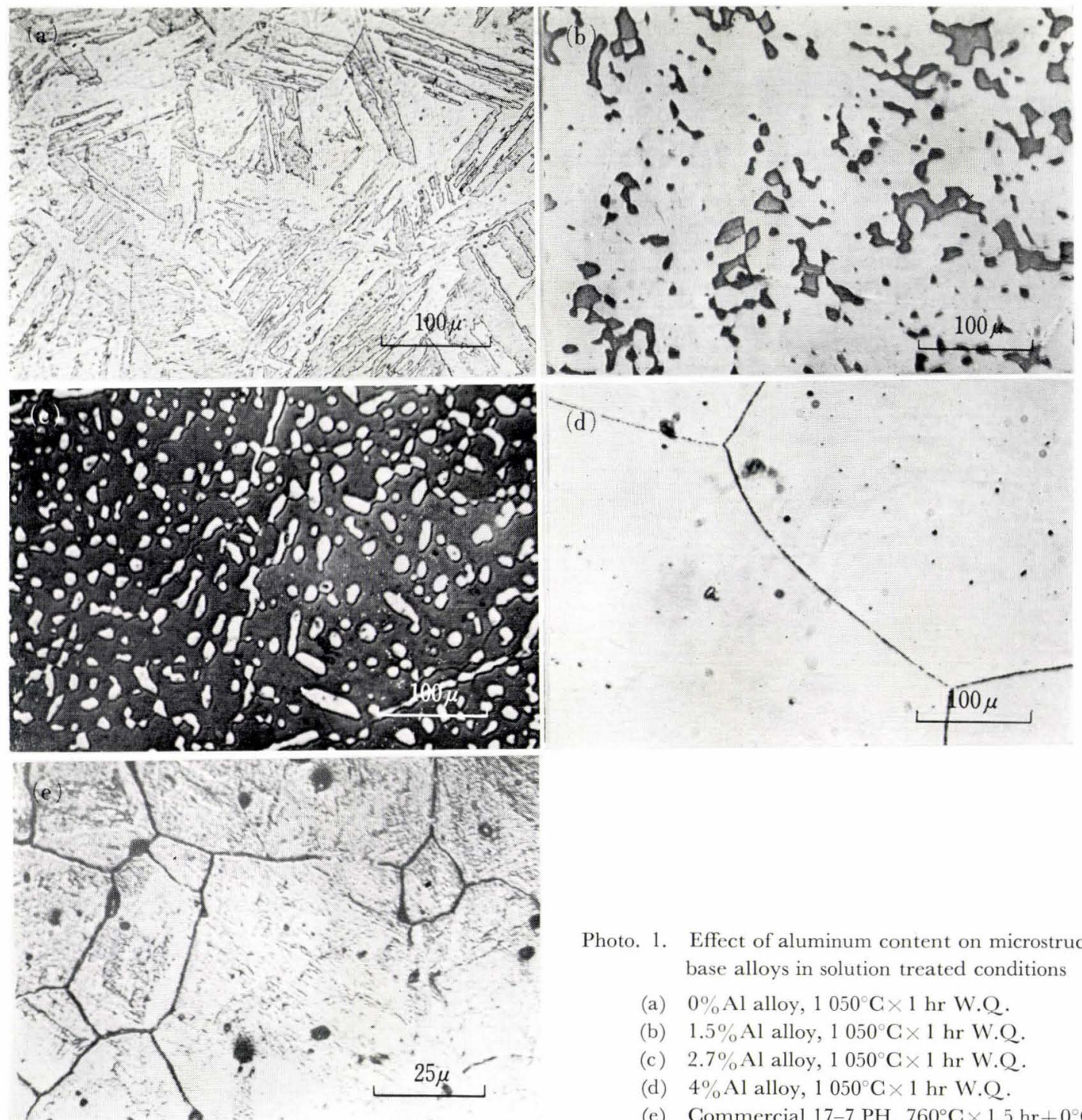

(d)

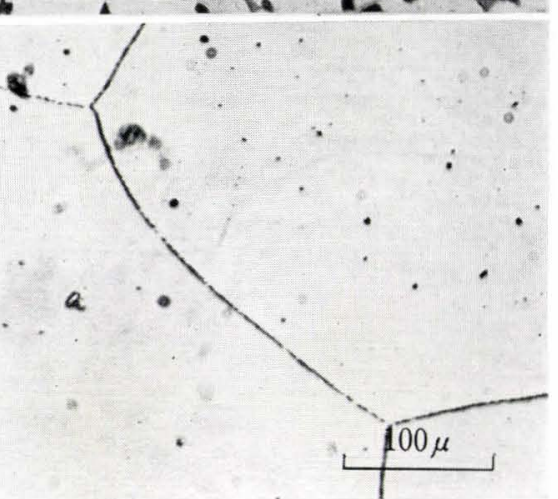

Photo. 1. Effect of aluminum content on microstructures of $17 \mathrm{Cr}-7 \mathrm{Ni}-\mathrm{Fe}$ base alloys in solution treated conditions

(a) $0 \% \mathrm{Al}$ alloy, $1050^{\circ} \mathrm{C} \times 1 \mathrm{hr}$ W.Q.

(b) $1.5 \% \mathrm{Al}$ alloy, $1050^{\circ} \mathrm{C} \times 1 \mathrm{hr}$ W.Q.

(c) $2.7 \% \mathrm{Al}$ alloy, $1050^{\circ} \mathrm{C} \times 1 \mathrm{hr}$ W.Q.

(d) $4 \% \mathrm{Al}$ alloy, $1050^{\circ} \mathrm{C} \times 1 \mathrm{hr}$ W.Q

(e) Commercial $17-7 \mathrm{PH}, 760^{\circ} \mathrm{C} \times 1.5 \mathrm{hr}+0^{\circ} \mathrm{C} \times 0.5 \mathrm{hr}$

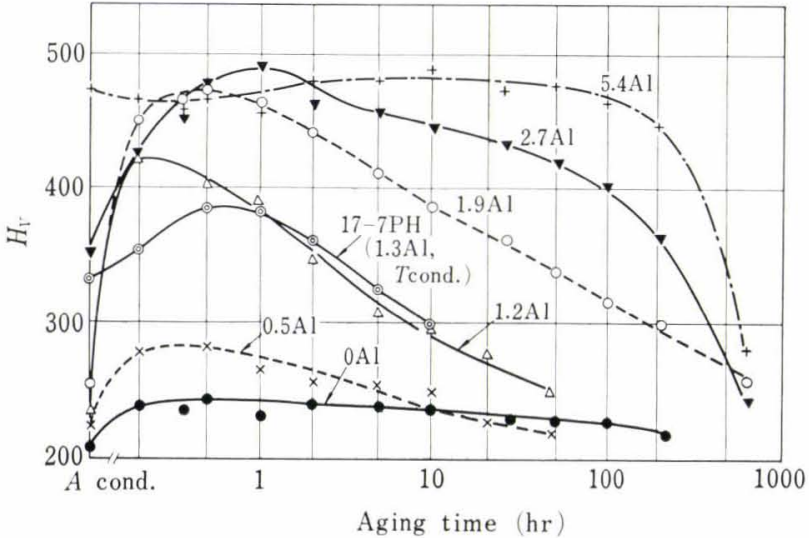

Fig. 7. Effect of $\mathrm{Al}$ on variation of hardness during isothermal aging at $600^{\circ} \mathrm{C}$ after $A$ treatment

alloys with similar aluminum content, i.e., $1.2 \%$ or $1.5 \% \mathrm{Al}$ alloys.

The case of $5.4 \% \mathrm{Al}$ alloy was exceptional. High initial hardness, about $H_{V}$ 460, was maintained up to $100 \mathrm{hr}$, followed by rapid softening. This anomaly can be interpreted as follows. Since the reaction $\alpha \rightarrow \alpha^{\prime}$ occurs at very high temperature in this alloy

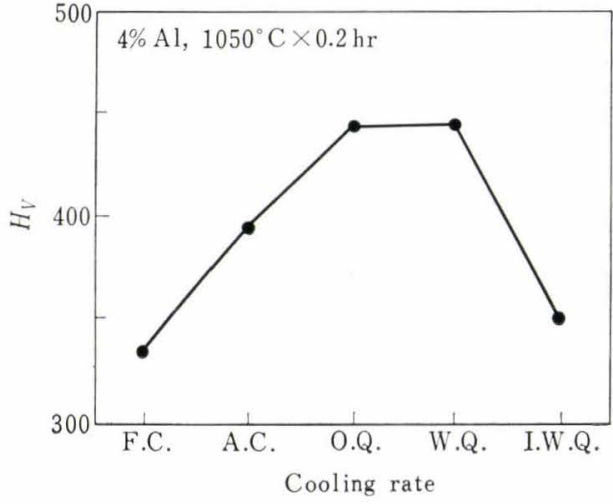

Fig. 8. Effect of cooling rate on hardness of $4 \% \mathrm{Al}$ alloy after $A$ treatment

as mentioned previously, the precipitation of $\alpha^{\prime}$ is so rapid that it cannot be suppressed even by water quenching in $A$ treatment. In order to assure this, the hardness of $4 \% \mathrm{Al}$ alloy, the age-hardening behavior of which was similar to that of $5.4 \% \mathrm{Al}$ alloy, was measured as the function of cooling rate from $1050^{\circ} \mathrm{C}$, and the result is shown in Fig. 8. It is interesting to 

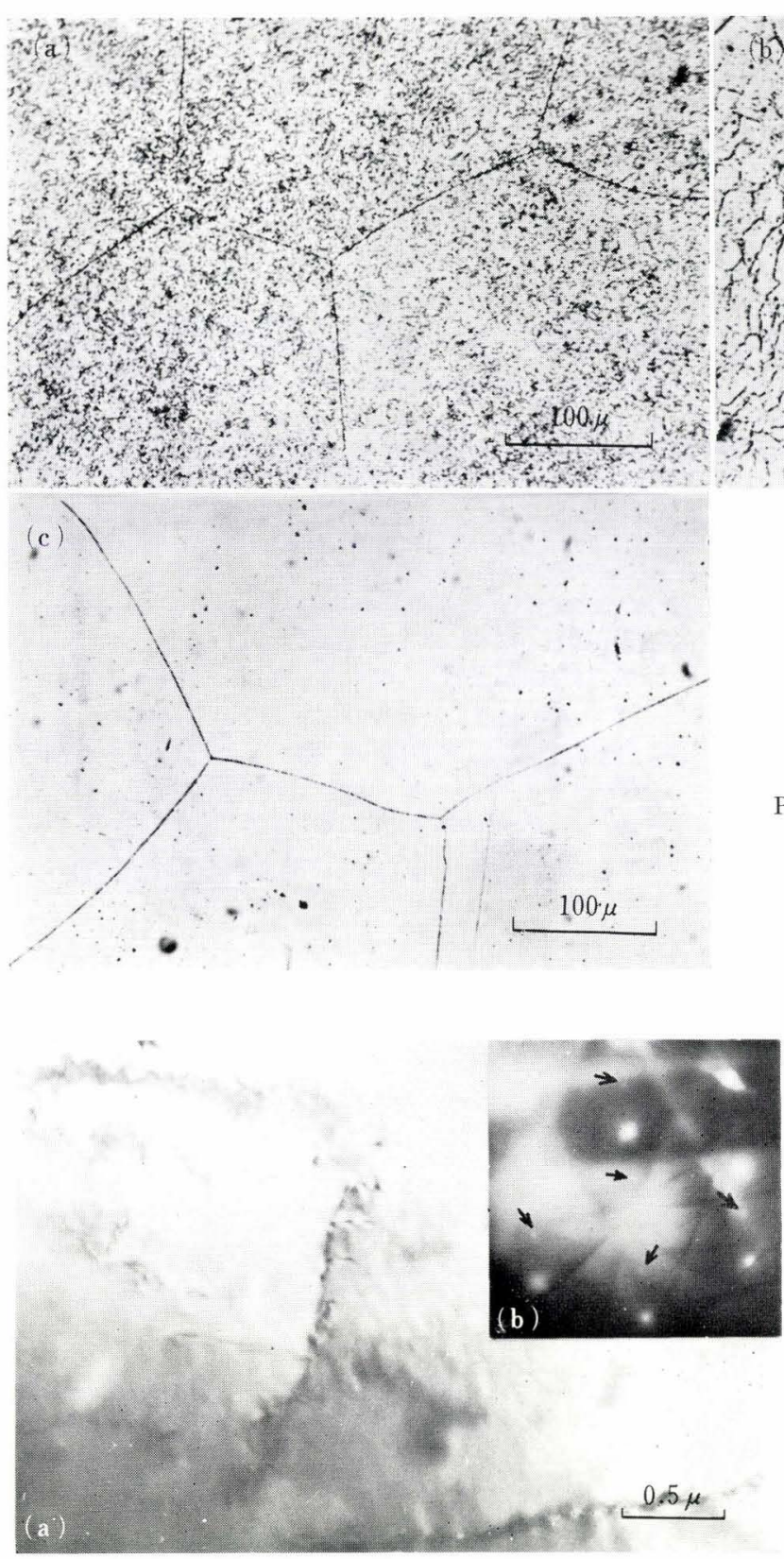

Photo. 3. Transmission electron micrograph of $5.4 \% \mathrm{Al}$ alloy water quenched from $1050^{\circ} \mathrm{C}$. Electron diffraction pattern exhibits the definite "super-lattice spots" (indicated by arrows) in addition to matrix spots, showing that $\alpha^{\prime}$ precipitates with complete coherency with $\delta$-ferrite matrix

note that the maximum hardness was obtained in water and oil quenching while the other cooling conditions resulted in lower hardness. Photograph 2 shows the microstructures after cooling. In furnace and air cooled conditions the precipitation of $\alpha^{\prime}$ was observed even by optical microscope, while in the other conditions the precipitation was hardly distinguished. Photograph 3 is the transmission electron micrograph of $5.4 \% \mathrm{Al}$ alloy as water quenched from $1050^{\circ} \mathrm{C}$, showing the grain boundaries and dislocations but not any precipitate. However, electron diffraction pattern taken on this specimen exhibits the definite "super-
Photo. 2. Effect of cooling rate on structure of precipitation of $\alpha^{\prime}$ during cooling in $4 \% \mathrm{Al}$ alloy

(a) $1050^{\circ} \mathrm{C} \times 10 \mathrm{~min}$ F.C. $H_{V} 336$

(b) $1050^{\circ} \mathrm{C} \times 10 \mathrm{~min} \mathrm{A.C.} H_{V} 396$

(c) $1050^{\circ} \mathrm{G} \times 10 \mathrm{~min}$ O.Q. $H_{V} 442$

lattice spots" in addition to the matrix $b c c$ spots. Since the lattice parameter of $\alpha^{\prime}$ is practically identical to that of matrix, the contrast of precipitates is so weak that they can not be observed even by transmission electron microscopy. From these results, it is concluded that by ice water quenching the precipitation of $\alpha^{\prime}$ is suppressed at least partially so that lower hardness is obtained, while by water and by oil quenching $\alpha^{\prime}$ precipitates submicroscopically and remarkable hardening occurs. On the other hand, by air and furnace cooling $\alpha^{\prime}$ precipitates become too gross to strengthen the matrix, so that the hardness decreases again.

Figure 9 shows the age-hardening curves at $500^{\circ} \mathrm{C}$. Although the hardening characteristics were very similar to those at $600^{\circ} \mathrm{C}$, the rate of hardening was much slower than that of at $600^{\circ} \mathrm{C}$.

In the age-hardening curves described above, the difference in the hardening characteristics between $\alpha_{M^{-}}$and $\delta$-phases was worth noticing. Figure 10 shows the change in micro-vickers hardness during aging at $550^{\circ} \mathrm{C}$ in $\alpha_{\mathrm{M}^{-}}$and $\delta$-crystals of $1.5 \% \mathrm{Al}$ and $1.9 \% \mathrm{Al}$ alloys. To obtain coarse crystal grains, the alloys were annealed at $1200^{\circ} \mathrm{C}$ for $1 \mathrm{hr}$, followed by solution treatment at $1050^{\circ} \mathrm{C}$. It is obvious that the hardening occurs not only in $\alpha_{\mathrm{M}}$ but also in $\delta$, but the hardening in $\alpha_{\mathrm{M}}$ is a little larger than $\delta$. This may be explained by taking into account that the amount of dislocation and $\mathrm{M}_{23} \mathrm{C}_{6}$ precipitate in $\alpha_{\mathrm{M}}$ is essentially larger than in $\delta$.

Figures 11 (a) and (b) show the effect of aluminum content on the hardness of the alloys aged for $0.5 \mathrm{hr}$ at $500^{\circ}$ and $600^{\circ} \mathrm{C}$, respectively. The difference between the aged hardness $\left(H_{a g}\right)$ and the hardness in the solution treated condition $\left(H_{a}\right)$ is designated as the 


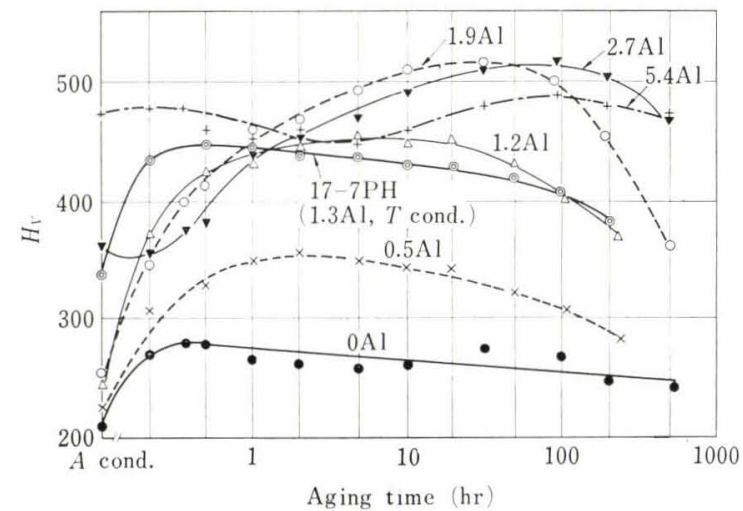

Fig. 9. Effect of $\mathrm{Al}$ content on variation of hardness during isothermal aging at $500^{\circ} \mathrm{C}$ after $A$ treatment

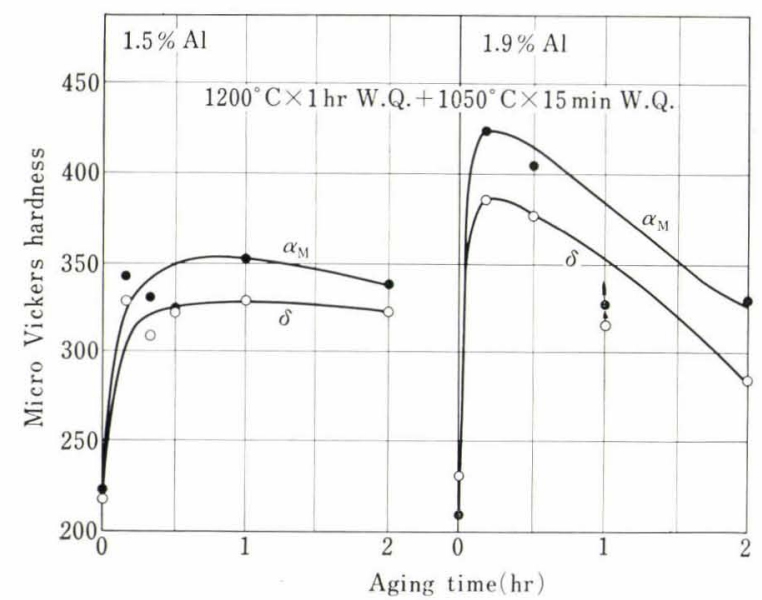

Fig. 10. Comparison of hardening in martensite with that in $\delta$-ferrite in 1.5 and $1.9 \% \mathrm{Al}$ alloys during isothermal aging at $550^{\circ} \mathrm{C}$ after $A$ treatment

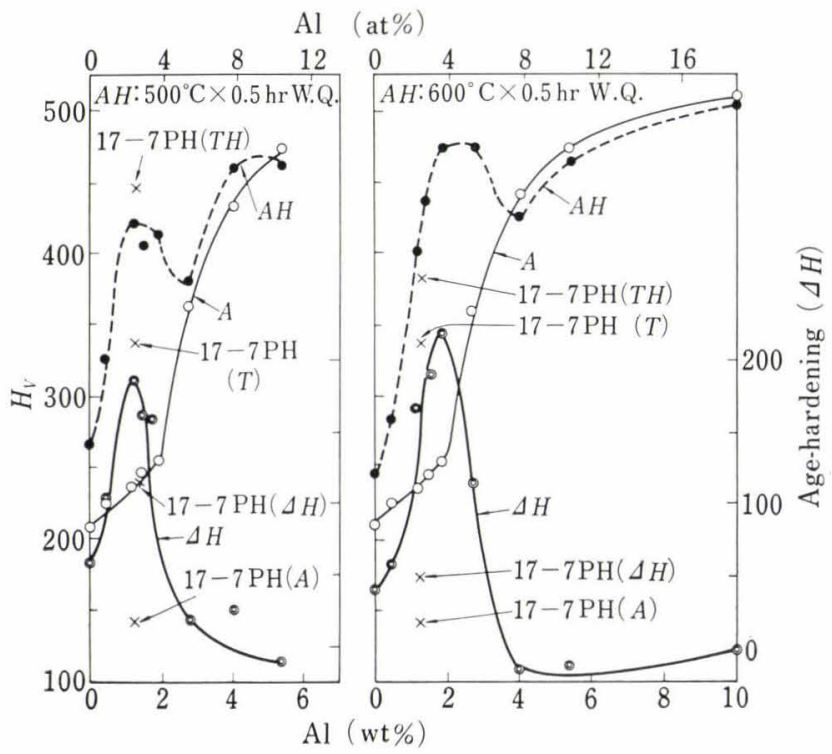

Fig. 11. Effect of $\mathrm{Al}$ content on hardness of specimens aged for $30 \mathrm{~min}$ at $500^{\circ}$ and $600^{\circ} \mathrm{C}$, respectively

measure of age-hardening $(\Delta H)$, that is $\Delta H=H_{a g}-H_{a}$. In the general view, the hardness increased with aluminum content, but there existed the maximum hardness near $1 \% \mathrm{Al}$ and minimum near $3 \% \mathrm{Al}$ in the case of $500^{\circ} \mathrm{C}$ aging, and the maximum near $2 \% \mathrm{Al}$ and minimum near $4 \% \mathrm{Al}$ in the case of $600^{\circ} \mathrm{C}$ aging, respectively. These features in hardening can be rationalized as follows: in those alloys which consist of $\alpha_{\mathrm{M}}$ alone, the hardness increases with aluminum content because of the increase in amount of $\alpha^{\prime}$ precipitation. In those alloys which consist of $\alpha_{\mathrm{M}}$ and $\delta$, the amount of $\alpha^{\prime}$ precipitation increases with aluminum content, but at the same time the amount of $\delta$-phase in the matrix increases, hence the hardness exhibits the peak at a certain aluminum content, since the hardening of $\delta$ is smaller than that of $\alpha_{\mathrm{M}}$ as shown in Fig. 10. In the alloys consisting of $\delta$ alone, the hardness increases with aluminum content again, since the $\alpha^{\prime}$ precipitation increases in amount with aluminum content. But the precipitation reaction in these alloys is so rapid that it cannot be suppressed by $A$ treatment ordinarily used. Accordingly, they show no perceptible hardening on subsequent aging ( $A H$ treatment). In Fig. 11 the hardness of commercial $17-7 \mathrm{PH}$ in $A, T$, and $T H$ treated conditions are also plotted. It is clear that the aluminum content of $17-7 \mathrm{PH}$ steel falls exactly in the optimum point for age-hardening.

\section{Summary}

In order to clarify the nature of age-hardening in 17-7 PH stainless steel, the constitution of alloys containing 16 to $19 \% \mathrm{Cr}, 7 \% \mathrm{Ni}, 0$ to $10 \% \mathrm{Al}$ and the remainder iron was investigated physico-metallurigically, and also the effect of aluminum upon age-hardening characteristics of the alloys was studied.

In this system, there exist $\alpha(\delta: b c c)$-, $\alpha^{\prime}$ (ordered $b c c$ CsCl type based on NiAl)-, and $\gamma(f c c)$-phases, of which the last $\gamma$-phase is transformed into martensite $\left(\alpha_{\mathrm{M}}\right)$ by quenching from $1050^{\circ} \mathrm{C}$. On subsequent aging between $400^{\circ}$ and $600^{\circ} \mathrm{C}, \alpha^{\prime}$ precipitates from both $\alpha_{\mathrm{M}}$ and $\delta$ matrices.

In commercial $17-7 \mathrm{PH}$ steel containing about $0.07 \% \mathrm{C}, \mathrm{M}_{23} \mathrm{C}_{6}$ is formed in addition to the abovementioned phases. In this case, however, $\gamma$ is so stable that it is retained to room temperature by quenching from $1050^{\circ} \mathrm{C}$. On annealing this metastable $\gamma$ at about $800^{\circ} \mathrm{C}$, it is transformed into $\alpha_{\mathrm{M}}$ by subsequent cooling owing to the precipitation of $\mathrm{M}_{23} \mathrm{C}_{6}$. On further aging between $400^{\circ}$ and $600^{\circ} \mathrm{C}, \alpha^{\prime}$ as well as $\mathrm{M}_{23} \mathrm{C}_{6}$ submicroscopically precipitates from $\alpha_{\mathrm{M}}$ and $\delta$ matrices, but the amount of the latter precipitate is negligibly small.

The age-hardening of alloys free from $\delta(0$ to $1.2 \% \mathrm{Al})$ is enhanced markedly with aluminum content owing to an increase of $\alpha^{\prime}$ precipitates. In alloys with $\delta$ alone $(>4 \% \mathrm{Al})$, however, $\alpha^{\prime}$ precipitates so rapidly that it cannot be suppressed even by water-quenching after solution treatment, and hence no appreciable age-hardening is observed on subsequent aging. Thus, the maximum hardening is obtained in alloys which consists of $\alpha_{\mathrm{M}}$ and a small amount of $\delta$ with about $1.5 \% \mathrm{Al}$ corresponding to the aluminum content of the standard 17-7 PH steel.

In commercial 17-7 $\mathrm{PH}$ steel, $\mathrm{M}_{23} \mathrm{C}_{6}$ carbide also precipitates from the matrix during aging, which, however, seems unlikely to be responsible for the age- 
hardening of this steel, because its amount is negligibly small.

Considering the results of the present experiments, the remarkable age-hardening of 17-7 PH steel was attributed to the precipitation of $\alpha^{\prime}$ from $\alpha_{\mathrm{M}}$.

\section{Acknowledgements}

The authors wish to express their cordial thanks to Dr. S. Takeda, professor emeritus of Nagoya University, for his encouragement and valuable discussion. They also desire to express their obligation to Nippon Yakin Kogyo Co. Ltd., who kindly sent materials for the writers' use.

\section{REFERENCES}

1) N. Yukawa, M. Mizutani, and H. Saka: J. Japan Inst. Metals, 31 (1967), 846 (in Japanese).

2) N. Yukawa, M. Mizutani, and H. Saka: J. Japan Inst. Metals, 31 (1967), 850 (in Japanese).

3) N. L. Carwile and S. J. Rosenberg: WADG TR 58-653
(1959).

4) H. C. Burnett, R. H. Duff, and H. C. Vacher : J. Res. Nat. Bureau of Standards, 66C (1962), 113.

5) E. E. Underwood, A. E. Austin, and G. K. Manning: J. Iron Steel Inst., 200 (1962), 644.

6) H. Marcus, L. H. Schwartz, and M. E. Fine: Trans. Amer. Soc. Metals, 58 (1965), 176.

7) H. Marcus, L. H. Schwartz, and M. E. Fine: Trans. Amer. Soc. Metals., 59 (1966), 468.

8) T. Furukawa: J. Japan Inst. Metals, 29 (1965), 34 (in Japanese).

9) T. Furukawa and O. Miyagawa: J. Japan Inst. Metals, 30 (1966), 1167 (in Japanese).

10) T. Furukawa: J. Japan Inst. Metals, 32 (1968), 105 (in Japanese).

11) H. C. Friedler, B. L. Averbach, and M. Cohen: Trans. Amer. Soc. Metals, 47 (1955), 267.

12) G. Krauss and B. L. Averbach: Trans. Amer. Soc. Metals, 52 (1960), 434.

13) R. H. Aborn and E. C. Bain : Trans. ASST, 18 (1930), 837. 